Sharif University of Technology
Scientia Iranica
SCIENTIA
IRAN ICA
http://scientiairanica.sharif.edu

\title{
Discharge and flow field simulation of open-channel sewer junction using artificial intelligence methods
}

\author{
A.H. Zaji and H. Bonakdari* \\ Department of Civil Engineering, Razi University, Kermanshah, Iran.
}

Received 13 December 2016; received in revised form 23 June 2017; accepted 29 August 2017

\section{KEYWORDS}

Discharge prediction; Gene expression programming; Multiple non-linear regression; Open channel; Radial basis neural network; Sewer junction; Velocity field.

\begin{abstract}
One of the most important parameters in designing sewer structures is the ability to accurately simulate their discharge and velocity field. Among the various sewer receiving inflow methods, open-channel junctions are the most frequently utilized ones. Because of the existence of separation and contraction zones in the open-channel junctions, the fluid flow has a complex behavior. Modeling is carried out by Radial Basis Function (RBF) neural network, Gene Expression Programming (GEP), and Multiple Non-Linear Regression (MNLR) methods. Finding the optimum situation for GEP and RBF models is done by examining various mathematical and linking functions for GEP, different numbers of hidden neurons, and various spread amounts for RBF. In order to use the models in practical situations, three equations were conducted by using the RBF, GEP, and MNLR methods in modeling the longitudinal velocity. Then, the surface integral of the presented equations was used to simulate the flow discharge. The results showed that the GEP and RBF methods performed significantly better than the MNLR in open-channel junction characteristics simulations. The GEP method had better performance than the RBF in modeling the longitudinal velocity field. However, the RBF presented more reliable results in the discharge simulations.
\end{abstract}

(C) 2019 Sharif University of Technology. All rights reserved.

\section{Introduction}

Sewer junctions are widely used in the drainage structures to collect the waste water. Fluid flows rarely fill the sewers under pressure. Instead, they often flow with air above the free surface and follow the open-channel hydraulic terms [1]. Junctions are one of the most typical inflow receiver structures in sewers [2]. Due to the importance of modeling of the fluid flow around junctions, the complex hydrodynamics of downstream flow have been studied in various researches, such as experimental studies [3-11], analytical

\footnotetext{
*. Corresponding author. Tel.: +98 8314274537 ;

Fax: +988314283264

E-mail address: bonakdari@yahoo.com (H. Bonakdari)
}

investigations [12-14], and numerical modeling [15$22]$.

In the recent years, soft computing methods have widely been used in various engineering problems [2327]. Complex flow velocity in the rivers was simulated by Kisi and Cigizoglu [28] using the RBF neural network. Bilhan et al. [29] simulated the side weir flow characteristics by using the RBF neural network. Azamathulla et al. [30] used GEP for modeling the accurate Manning roughness coefficient. Zaji and Bonakdari [31] used the Multi-Layer Perceptron Artificial Neural Network (MLP-ANN) and Genetic Programming (GP) in modeling the velocity field around junctions. Bonakdari and Zaji [32] introduced a new Genetic Algorithm (GA) based Artificial Neural Network (GA-ANN) method in order to simulate the open-channel junction velocity field without needing to adjust the hidden layer neurons. The authors con- 
cluded that GA-ANN method had better performance than other GA methods such as GP.

The aim of the present study is to obtain an analytical and, thus, continuous description of the complex discharge and velocity fields of open-channel sewer junction using the discrete laboratory measurements. To do that, some popular regression methods, namely, RBF, GEP, and MNLR, are developed. In the modeling procedure, the non-dimensional coordinate points $\left(x^{*}, y^{*}\right.$, and $\left.z^{*}\right)$ and junction discharge ratio $\left(q^{*}\right)$ are considered as the input variable candidates to predict the discharge and velocity fields. After finding the optimum input combination, three different equations are proposed to simulate the downstream longitudinal flow field of the junction in the practical situations. Finally, the surface integral is used to reach the discharge simulation of the junction.

\section{Experimental data}

Weber et al. [11] performed a high quality experimental study on open-channel junctions, which has been utilized in various Computational Fluid Dynamic (CFD) studies in order to calibrate and validate the numerical models $[16,17,20]$. The result of the experimental measurements of Weber et al. [11] was used in this study in the training and testing processes of the investigated models. The experiments were performed in a junction flume with $0.91 \mathrm{~m}$ width and $90^{\circ}$ confluence between the main and tributary channels. The floor of the flume was horizontal and two head tanks were on the main and branch channels to supply the discharge. In order to have a completely developed flow near the junction, some perforated plates and honeycomb were placed at the beginning of the main and branch channels. The schematic overview of the laboratory flume is shown in Figure 1. The coordinates of each point were
Table 1. The considered discharge ratios.

\begin{tabular}{ccc}
\hline $\boldsymbol{Q}_{\boldsymbol{m}}\left(\mathbf{m}^{\mathbf{3}} / \mathbf{s}\right)$ & $\boldsymbol{Q}_{\boldsymbol{t}}\left(\mathbf{m}^{\mathbf{3}} / \mathbf{s}\right)$ & $\boldsymbol{q}^{*}$ \\
\hline 0.014 & 0.156 & 0.083 \\
0.042 & 0.127 & 0.250 \\
0.071 & 0.099 & 0.417 \\
0.099 & 0.071 & 0.583 \\
0.127 & 0.042 & 0.750 \\
0.156 & 0.014 & 0.914 \\
\hline
\end{tabular}

non-dimensionalized by the channel width $\left(x / b=x^{*}\right.$, $y / b=y^{*}$, and $\left.z / b=z^{*}\right)$. The longitudinal velocity was non-dimensionalized with the tail water velocity that remained constant in the experiments $\left(u^{*}=u / 0.628\right)$. $q^{*}$ in Eq. (1) is the ratio of the upstream to downstream main channel discharges.

$$
q^{*}=\frac{Q_{m}}{Q_{m}+Q_{t}}
$$

where $Q_{m}$ is the upstream main channel discharge and $Q_{t}$ is the tributary discharge. This study was conducted with various amounts of $q^{*}$, which are shown in Table 1.

\section{Methodology}

In this section, the used numerical methods are investigated. Afterwards, the statistics that are used in order to evaluate performance of the model are represented.

\subsection{Radial Basis Function (RBF) neural network}

Because of advantages such as easy design, high tolerance to input noise, good generalization of the nonlinear problems, and the ability of online learning, RBF has become one of the most popular neural network methods. The RBF $[33,34]$ consists in some

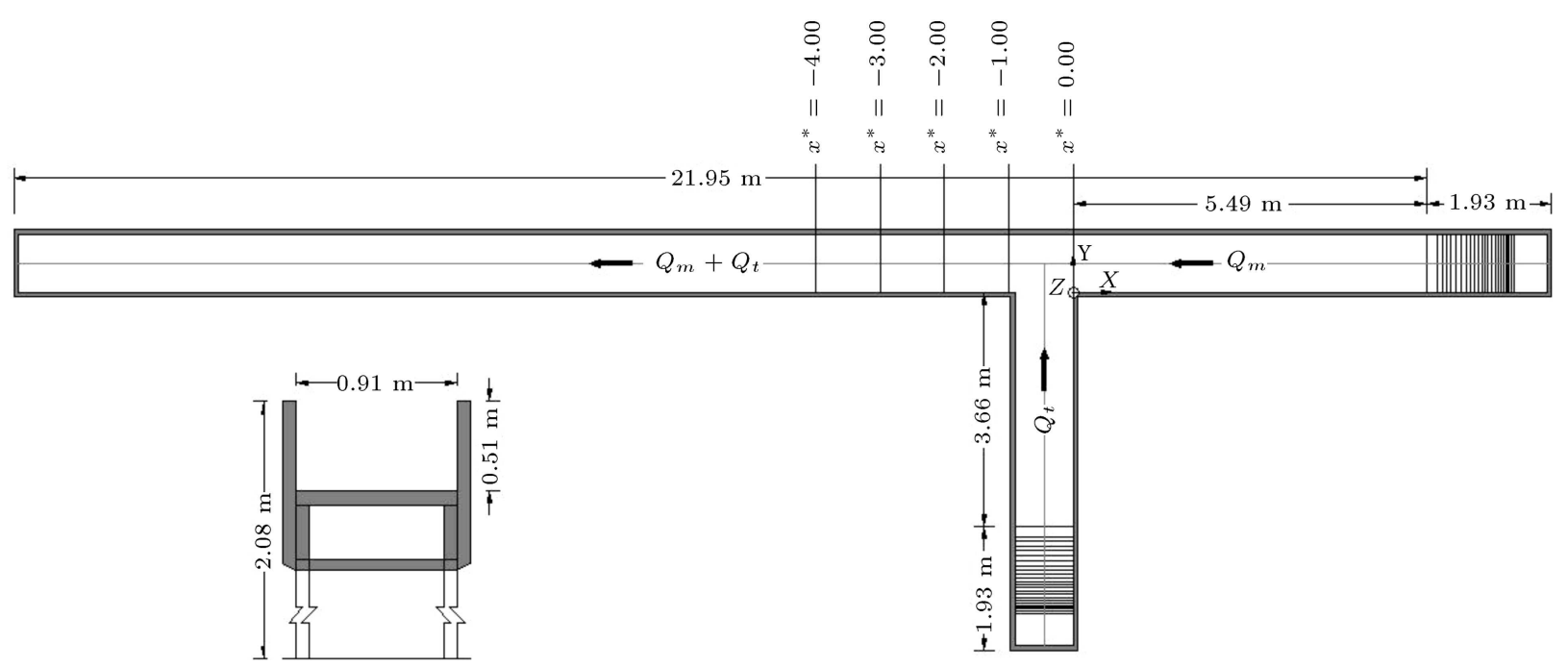

Figure 1. Schematic overview of the laboratory flume of Weber et al. [11]. 
radial functions. The amounts of the radial functions are directly related to the distance from the origin [35]. Input layer transforms the input variables into nonlinear space by using the radial functions. After that, the output layer prepares the output of the model by using a linear regression between the radial functions. To this end, the output layer performs weighted summation of the radial functions. Weight of each radial function indicates the impact of that function on the model output. These weights are determined by using the least squares method. The value of a radial basis, which is shown by $\varphi(x, c)$, increases with the radial distance $r=\|x-c\|$, where $x$ is the input and $c$ is the radial function center. A radial function with $N$ dimensions and the linear regression result of an RBF are shown in Eqs. (2) and (3), respectively.

$$
\begin{aligned}
& \left\{\varphi\left(\| x-x_{i}||\right) \mid i=1,2, \cdots, N\right\} \\
& f(x)=\sum_{i=1}^{N} c_{i} \varphi\left(\left\|x-x_{i}\right\|\right) .
\end{aligned}
$$

With regards to the characteristic of linear determination of the radial functions in the output layer, the RBF neural network is considered as one of the fast convergence neural networks [36].

Determination of the correct number of hidden layer neurons and the spread amount is one of the most important processes of the RBF modeling and directly affects the model performance. Trial and error method is applied in this study to the RBF code in order to determine the appropriate number of hidden neurons and spread amount $[28,36]$.

\subsection{Gene Expression Programming (GEP)}

The GEP, as a developed model of GP [37], is a computer program based method. The output of this method is presented by some subtrees that are linked with each other by linking mathematical functions. The algorithm of the GEP method is similar to that of the GA. However, GEP uses the computer programs instead of chromosomes in GA. First, the computer programs of the initial population are randomly generated and, after that, the cost of each computer program is determined by using the considered fitness function. Afterwards, by using the elite, mutation, and crossover processes, the next generation is constructed. GEP follows an evolutionary process and generation reconstruction is repeated until it reaches the determined number of generations or accuracy $[38,39]$.

In this study, various functions, which are allowed to be used in the computer programs, and different subtree linking functions are investigated in order to find the optimum GEP model. Other parameters of the models are presented in Table 2 according to Ferreira [39].
Table 2. GEP default parameters.

\begin{tabular}{ll}
\hline \multicolumn{1}{c}{ Parameter } & \multicolumn{1}{c}{ Properties } \\
\hline Number of generations & 40000 \\
Number of chromosomes & 30 \\
Head size & 8 \\
Number of genes & 3 \\
Fitness function & Root mean square error \\
Mutation rate & 0.044 \\
Inversion rate & 0.1 \\
One-point recombination rate & 0.3 \\
Two-point recombination rate & 0.3 \\
Gene recombination rate & 0.1 \\
Gene transposition rate & 0.1 \\
\hline
\end{tabular}

\subsection{Statistical errors}

In order to have a comparison between the numerical models, the Mean Square Error (MSE), correlation coefficient $(R)$, Mean Absolute Error (MAE), average absolute deviation $(\% \delta)$, Scatter Index (SI), and BIAS are used. The closer the amounts of the MSE, MAE, $\% \delta$, SI, and BIAS indices to zero and the closer the amount of $R$ to one, the higher the performance of the models will be. The considered statistics are described in Eqs. (4)-(9).

$$
\begin{aligned}
& M A E=\left(\frac{1}{n}\right) \sum_{i=1}^{n}\left|u_{i, o}^{*}-u_{i, e}^{*}\right|, \\
& R=\frac{\sum_{i=1}^{n}\left(u_{i, o}^{*}-\bar{u}_{o}^{*}\right)\left(u_{i, e}^{*}-\bar{u}_{e}^{*}\right)}{\sqrt{\sum_{i=1}^{n}\left(u_{i, o}^{*}-\bar{u}_{o}^{*}\right)^{2} \sum_{i=1}^{n}\left(u_{i, e}^{*}-\bar{u}_{e}^{*}\right)^{2}}}, \\
& M S E=\left(\frac{1}{n}\right) \sum_{i=1}^{n}\left(u_{i, o}^{*}-u_{i, e}^{*}\right)^{2}, \\
& \% \delta=\frac{\sum_{i=1}^{n}\left|u_{i, e}^{*}-u_{i, o}^{*}\right|}{\sum_{i=1}^{n} u_{i, e}^{*} \times 100,} \\
& B I A S=\frac{\sqrt{(1 / n) \sum_{i=1}^{n}\left\{\left[u_{i, e}^{*}-\bar{u}_{e}^{*}\right]-\left[u_{i, o}^{*}-\bar{u}_{o}^{*}\right]\right\}^{2}}}{(1 / n) \sum_{i=1}^{n} u_{i, o}^{*}}
\end{aligned}
$$

In this equations, $u_{i, o}^{*}$ and $u_{i, e}^{*}$ are the $i$ th nondimensional observed and estimated velocities, respectively, and $n$ is the number of investigated samples. 


\section{Results and discussion}

The aim of this section is to investigate the RBF, GEP, and MNLR methods in the open-channel junction longitudinal velocity field and discharge simulations. Using the laboratory measurements of Weber et al. [11], a total of 5466 samples are used in order to develop the models. Also, $80 \%$ of the entire dataset (4373 samples) are separated randomly for the training process, and the remaining 20\% (1093 samples) are considered as the testing dataset. The input variables of the models are non-dimensional coordinates of each point $x^{*}, y^{*}$, and $z^{*}$ as well as the discharge ratio $q^{*}$.

The results are presented in two parts. The goal of the first part is to simulate the non-dimensional longitudinal velocity, $u^{*}$, by using the investigated models. In addition, three different equations are proposed in this part that can simulate the velocity field in the practical situations. In the second part, by using the surface integral equation, the downstream discharges of the junction are simulated and the results of the investigated models are compared.

\subsection{Velocity field simulation}

The downstream longitudinal velocity field of the openchannel junction is simulated in this section. The performance of the RBF is directly related to the optimum selection of the model's parameters. In order to find the number of hidden layer neurons and the spread amount in the RBF neural network, two loops are added to the main RBF program, one for changing the spread amount and the other for changing the number of hidden layer neurons. Figure 2 shows the performance of each model with various spread amounts and hidden layer neuron numbers. In each situation, the performance of the model is represented by Root Mean Squared Error (RMSE). As it is shown in this figure, the RBF with 20 hidden layer neurons and the spread value of one has the most appropriate performance.
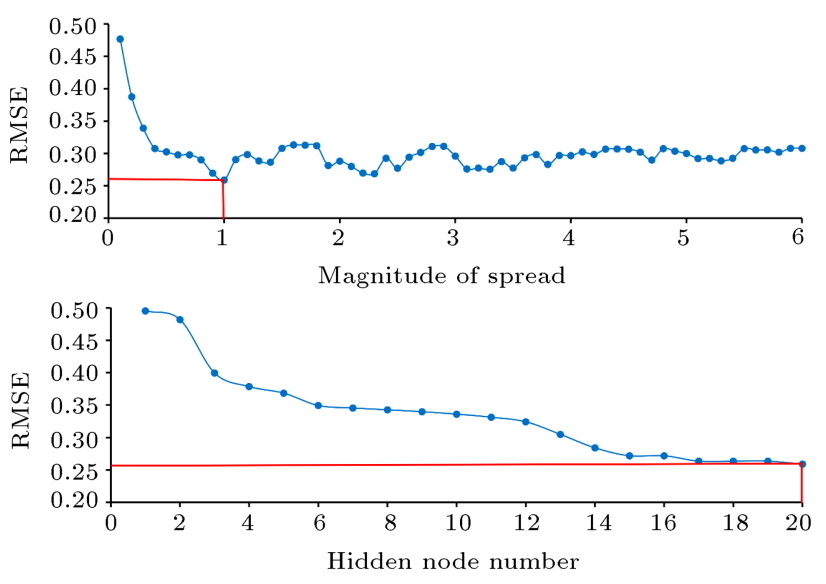

Figure 2. Spread and hidden neurons number determination of the RBF.
The RBF output is presented in Eq. (10):

$$
\begin{aligned}
& u^{*}=L W \times \exp \left(-\left(\left(\sum\left((I W \cdot-I N) \cdot{ }^{\wedge} 2\right)\right)\right.\right. \\
& \left.\left.\wedge^{\wedge} 0.5 . \times b_{1}\right) . \wedge 2\right)+b_{2}, \\
& I N=\left[\begin{array}{llll}
x^{*} & y^{*} & z^{*} & q^{*}
\end{array}\right], \\
& L W=\left[\begin{array}{llll}
-3.45 e 10 & -0.69 & -62.58 & 19.07
\end{array}\right. \\
& \begin{array}{llll}
61.35 & 3.09 & -258.21 \ldots & \ldots 251.28
\end{array} \\
& \begin{array}{lllll}
-18.21 & 209.07 & -199.33 & 1 e 10 & 0
\end{array} \\
& 0 \ldots \quad \ldots 8.64 e 10 \quad 0 \quad 1.07 e 11 \quad-1.75 e 10 \\
& -1.52 e 11 \quad-5.09] \\
& b_{1}=[0.83] \text {, } \\
& b_{2}=[-0.57] \text {, }
\end{aligned}
$$

$$
I W=\left[\begin{array}{cccc}
-2.33 & 0.87 & 0.27 & 0.41 \\
-4 & 0.87 & 0.3 & 0.41 \\
-2.66 & 0.25 & 0.27 & 0.41 \\
-1 & 0.87 & 0.27 & 0.58 \\
-2.66 & 0.05 & 0.3 & 0.41 \\
-3 & 0.87 & 0.04 & 0.41 \\
-2.33 & 0.05 & 0.27 & 0.41 \\
-2.33 & 0.12 & 0.27 & 0.41 \\
-1 & 0.75 & 0.27 & 0.58 \\
-2 & 0.05 & 0.27 & 0.41 \\
\vdots & & & \\
-2 & 0.12 & 0.27 & 0.41 \\
-2.33 & 0.87 & 0 & 0.41 \\
-2.33 & 0.87 & 0 & 0.41 \\
-2.33 & 0.87 & 0 & 0.41 \\
-2.33 & 0.87 & 0.25 & 0.41 \\
-2.33 & 0.87 & 0.01 & 0.41 \\
-2.33 & 0.87 & 0.16 & 0.41 \\
-2.33 & 0.87 & 0.02 & 0.41 \\
-2.33 & 0.87 & 0.19 & 0.41 \\
-2 & 0.05 & 0 & 0.41
\end{array}\right]
$$

where $I W$ and $L W$ are the RBF coefficients that are determined in the modeling process, $b_{1}$ and $b_{2}$ are biases of the model, and $I N$ is the input vector that contains the input variables of the model. It should be noted that in this equation, $\cdot \times, \cdot+$, and $\cdot \wedge$ are the cell-by-cell operations.

Various parameters affect the GEP performance. Among them, the mathematical functions allowed to be used in the computer programs are the most important ones. Six different mathematical function combinations are examined in this study in order to find the most 
Table 3. Considered mathematical function combinations.

\begin{tabular}{|c|c|c|}
\hline Function & Definition & RMSE \\
\hline$F 1$ & $+,-, \cdot, /$ & 0.3399 \\
\hline$F 2$ &,,$+- \cdot /, \sqrt{ }$, Power & 0.2456 \\
\hline$F 3$ &,,$+- \cdot /, \sqrt{ }$, Power, $\ln x, \log x, e^{x}, 10^{x}$ & 0.2620 \\
\hline$F 4$ &,,$+- \cdot /, \sqrt{ }$, Power, Average, Inverse & 0.2778 \\
\hline$F 5$ & $+,-, \cdot, /, \sqrt{ }, \sqrt[3]{ }$, Power, $\ln x, \log x, e^{x}, 10^{x}, x^{2}, x^{3}, \sin x, \cos x, \operatorname{arctg} x$, negative, inverse & 0.2534 \\
\hline$F 6$ & $+,-, \cdot, /, \sqrt{ }, \ln x, e^{x}, x^{2}, \operatorname{arctg} x$, Inverse, $\tanh x$, not, average, maximum, minimum & 0.2464 \\
\hline
\end{tabular}

Table 4. Statistical indices for trained and tested datasets.

\begin{tabular}{|c|c|c|c|c|c|c|c|c|c|c|c|c|}
\hline \multirow{2}{*}{ Models } & \multicolumn{6}{|c|}{ Training } & \multicolumn{6}{|c|}{ Testing } \\
\hline & MSE & MAE & $\boldsymbol{R}$ & $\delta$ & SI & BIAS & MSE & MAE & $\boldsymbol{R}$ & $\delta$ & SI & BIAS \\
\hline $\mathrm{RBF}$ & 0.063 & 0.184 & 0.869 & -22.403 & -0.305 & 0.00017 & 0.067 & 0.187 & 0.860 & -22.721 & -0.319 & -0.0124 \\
\hline GEP & 0.055 & 0.177 & 0.887 & -21.468 & -0.285 & -0.0045 & 0.056 & 0.179 & 0.885 & -22.000 & -0.291 & -0.0033 \\
\hline MNLR & 0.123 & 0.259 & 0.724 & -31.478 & -0.426 & -0.0003 & 0.137 & 0.268 & 0.685 & -32.697 & -0.457 & -0.0108 \\
\hline
\end{tabular}

appropriate one. According to Table 3, the F2 mathematical function combination with the RMSE of 0.2456 has the best performance among the models. Moreover, it is obvious that increasing the complexity of the mathematical function combinations does not always lead to better performance of the computer programs.

As mentioned before, GEP's output is constructed from some subtrees. Subtrees are linked with each other by using a determined linking function. Many studies have used additional linking functions to connect the output subtrees [30,40-44]. However, in this study, the division linking function with RMSE of 0.2361 has the best performance in comparison with the addition, subtraction, and multiplication linking functions with RMSEs of 0.2456, 0.2820, and 0.2491, respectively. The output of the GEP model by using the second mathematical function combination and division linking function is presented in Eq. (11).

$$
\begin{aligned}
& u^{*}=\left[\sqrt{\sqrt{\sqrt{\left(q^{*} \times z^{*}\right)\left(q^{* y^{*}}\right) \times y^{*}}}}\right] \\
& /\left[\left(\frac{z^{*}}{x^{*}} \times y^{* 2}\right)-y^{* y^{*}}\right] /\left[\frac{0.6730}{\sqrt{y^{* \sqrt{\frac{1.2522 \times z^{*}}{y^{*}}}}}}\right]
\end{aligned}
$$

Another method investigated in this study is MNLR. The MNLR tries to find a non-linear relationship between the considered input variables $\left(x^{*}, y^{*}, z^{*}\right.$, and $q^{*}$ ) and the output variable $\left(u^{*}\right)$. The MNLR output equation is presented in the following formula:

$$
u^{*}=(2.91)+(-0.02) \times x^{*(-99.36)}+(-4.27) \times y^{*(0.11)}
$$

$$
+(124.48) \times z^{*(6.23)}+(-104.31) \times q^{*(33.76)} .
$$

Performances of the RBF, GEP, and MNLR models are shown in Table 4. According to this table, the GEP, with MSE of 0.056 , has better performance than the RBF and MNLR models with MSEs of 0.067 and 0.137 , respectively. In addition, it is evident that the GEP and RBF models are significantly more accurate in simulating the open-channel junction longitudinal velocity field simulation. The close performances of the considered models in test and train datasets show that there is no over-training occurring in the models.

A comparison of the experimental measurements $u^{*}$ with the RBF, GEP, and MNLR predictions for $u^{*}$ is presented in Figures 3, 4, and 5, respectively. In each figure, the upper plot shows the comparison between the experimental and numerical $u^{*}$ for the entire test dataset and, in order to have a more detailed comparison, the lower plot compares the experimental
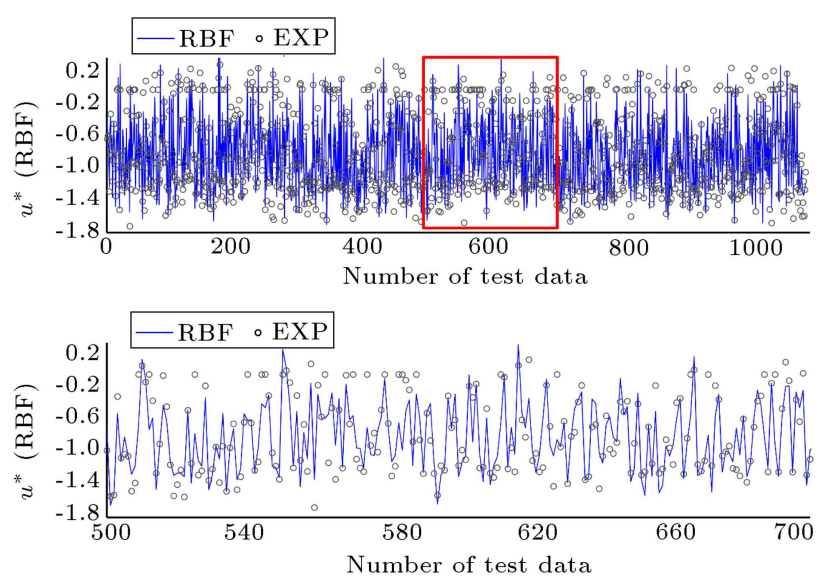

Figure 3. RBF modeling of $u^{*}$ in test dataset. 

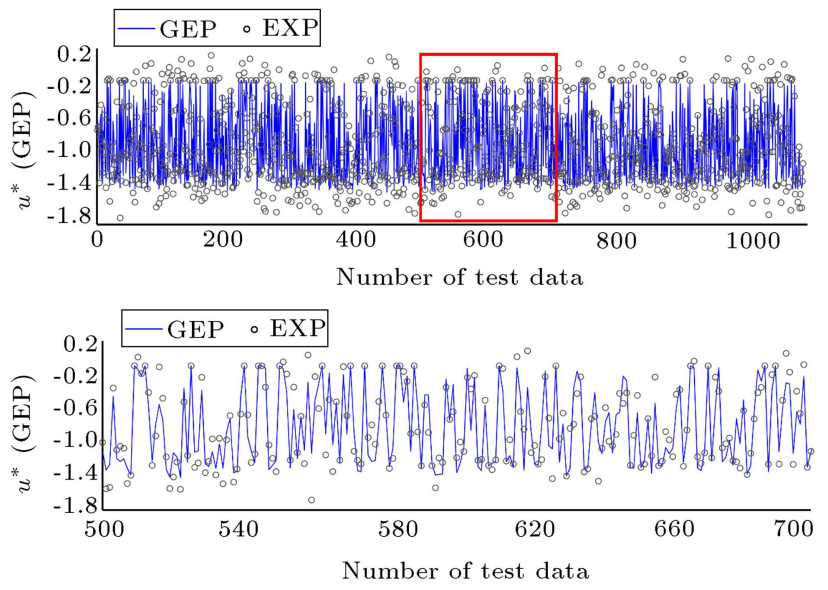

Figure 4. GEP modeling of $u^{*}$ in test dataset.
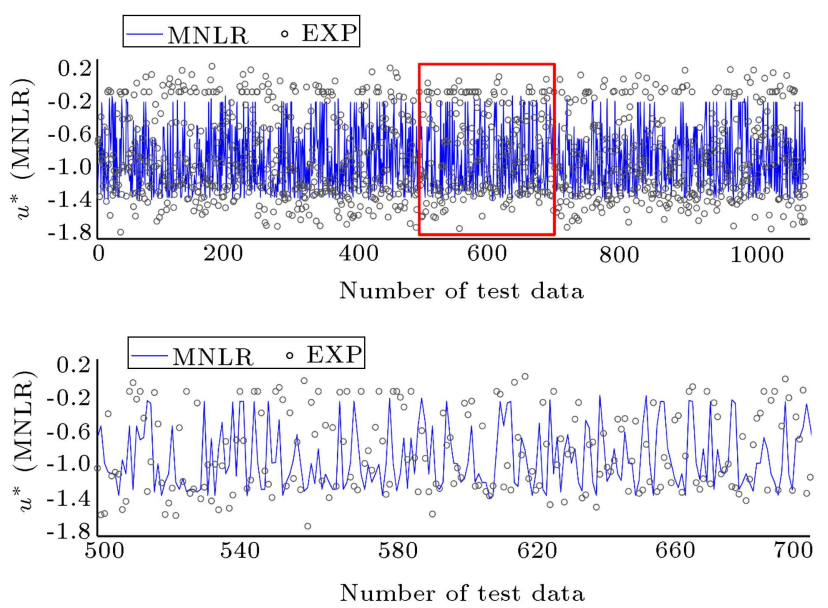

Figure 5. MNLR modeling of $u^{*}$ in test dataset.

and numerical $u^{*}$ for the 500th to 700th samples of the test dataset. From this figures, it can be seen that MNLR shows the worst performance in simulating the longitudinal velocity. The RBF and GEP models have close performances. However, according to the lower plots, it could be concluded that GEP has better performance in modeling the flow field in the openchannel junctions.

The scatter plots of the considered models for test and train datasets are presented in Figure 6 . In this figure, the red line represents the exact $45^{\circ}$ line. The closer the scatters of a model to the exact line, the higher the accuracy of the model will be. The blue line in the plots shows the trend line of each dataset. The trend line has the equation of $y=a x+b$ and closer $a$ and $b$ to one and zero, respectively, indicate the better performance of the models. From Figure 6 , it is evident that the GEP model with $a$ value of 0.7898 , $b$ value of 0.1736 , and $R^{2}$ value of 0.7828 , in the test dataset, has better performance than other models. The RBF model with $a, b$, and $R^{2}$ of $0.7474,0.2169$, and 0.7391 , respectively, in test dataset, also has a good performance, which is highly close to the GEP model.
The MNLR is the weakest model that cannot simulate the complex velocity field around the junctions to any degree.

\subsection{Discharge simulation}

Designing the sewer systems necessarily requires the ability to accurately predict the flow discharge. Because of the crucial role of discharge in sewer structures, there are many studies performed on this topic [4550]. Fortunately, using the $u^{*}$ simulation developed in the previous part and the surface integral on the cross section zones, the discharge of the junctions can be simulated. The discharge can be modeled by using $u^{*}$ according to the following equation:

$$
Q=\iint_{A} u^{*} d A
$$

where $Q$ is the discharge and $u^{*}$ is the longitudinal velocity of open-channel junction. In this equation, $A$ represents the cross sections that are investigated in the $x^{*}$ direction. In this study, the cross sections of $x^{*}=-1,-1.33,-1.66,-2,-2.33,-2.66,-3,-3.33$, and -3.66 are investigated according to Figure 1.

The results of the discharge simulation are plotted in Figure 7. In this figure, the discharges are simulated in various $q^{*}$ amounts. In the experimental study of Weber et al. [11], the junction outflow discharge remains constant in all conditions up to $0.17 \mathrm{~m}^{3} / \mathrm{s}$. Therefore, the experimental results are plotted with a straight black line in the figure. It is obvious that the models with closer values of simulated discharge to this line have better performances. In order to investigate the performance of each model in discharge simulation, the Standard Deviation (SD) concept is used (Eq. (14)):

$$
\mathrm{SD}=\sqrt{\frac{1}{N-1} \sum_{i=1}^{N}\left(\frac{\text { Res }_{i}-}{\text { lineRes }}\right)^{2}}
$$

where $\operatorname{Res}_{i}$ is the residual of the $i$ th simulated sample according to the experimental residual, $\overline{R e s}$ is the average of the entire dataset residuals, and $N$ is the number dataset's samples.

By definition, almost $95 \%$ of the dataset frequency is limited between Avg $-2 \times S D$ and Avg + $2 \times S D$. Avg is the average of the entire dataset. According to Figure 7, despite the velocity field prediction presented in the last part of results, the RBF model with $\operatorname{Avg}+2 \times S D$ of 0.180 has better performance than the GEP model with Avg $+2 \times S D$ of 0.182 . As an important result, the model with high accuracy in modeling of the flow field velocity may have a worse performance in modeling of the discharge. In fact, high accuracy of the models in discharge prediction is dependent on their capability of simulating the mean 

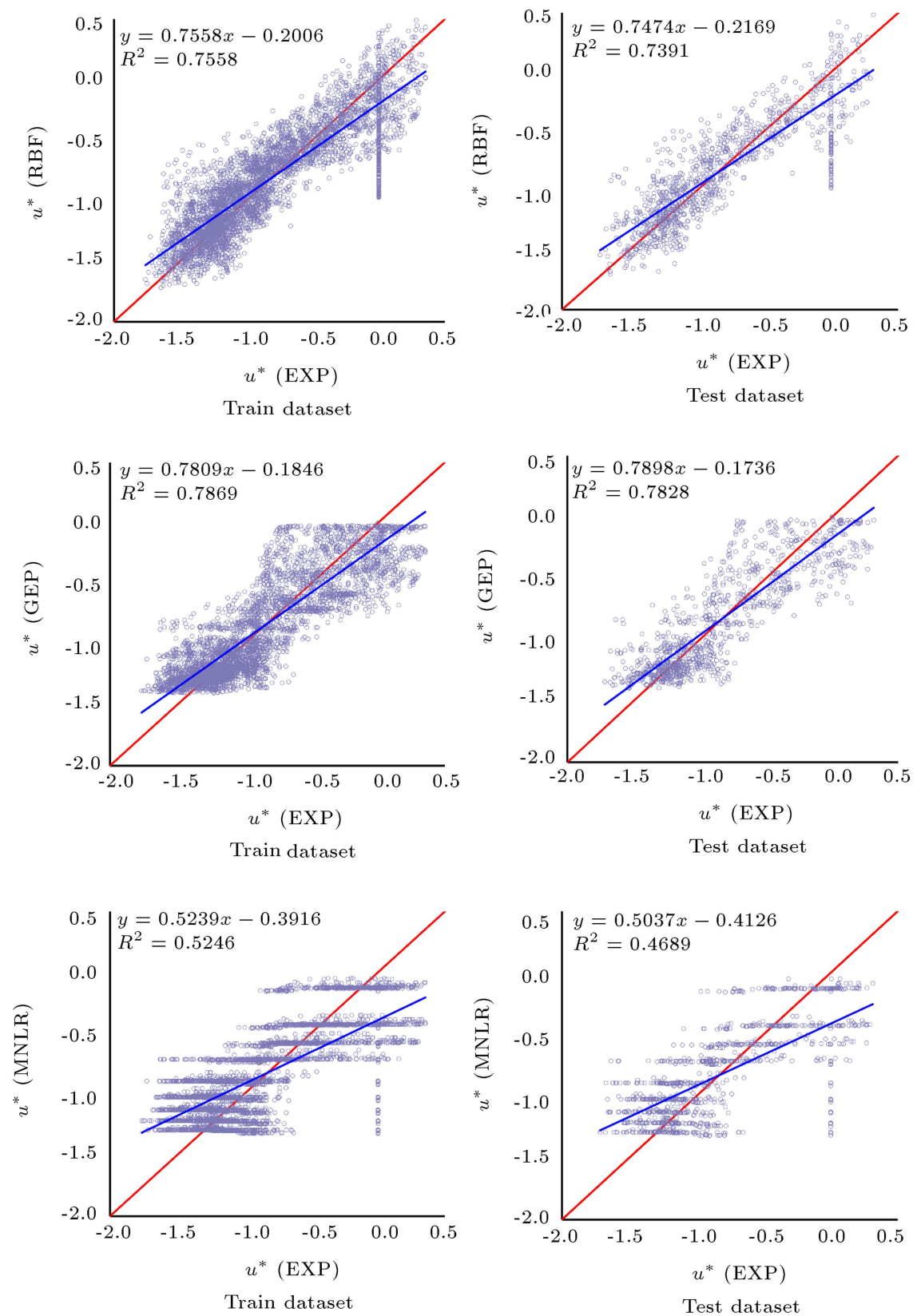

Figure 6. Experimental versus simulated $u^{*}$ by RBF, GEP, and MNLR models.

velocity of the investigated section. As in the previous section, the MNLR model has worse performance than the RBF and GEP models.

\section{Conclusion}

Simulating the velocity field and discharge of the sewer junctions was investigated in this study. In order to simulate the complex 3D downstream velocity field of the junction, the non-dimensional coordinates of each point $\left(x^{*}, y^{*}\right.$, and $\left.z^{*}\right)$ and discharge ratio $\left(q^{*}\right)$ were chosen as the input variables. The modeling processes were performed by using the RBF, GEP, and MNLR methods. In order to find the optimum RBF model, various numbers of hidden nodes and spread amounts were tested and the RBF with 20 hidden neurons and spread magnitude of one was chosen. The optimum GEP model was chosen by running the GEP with various linking and mathematical functions. Finally, the optimum GEP was found by using the combination of division linking function and $+,-, \cdot, / \sqrt{ }$, and Power mathematical functions. Using the developed models, three different equations for modeling the longitudinal velocity in the open-channel junction were presented. The results of the velocity field simulation showed that the GEP model performed better than the RBF and MNLR models. Afterwards, using the surface integral concept, discharge of the junction's 

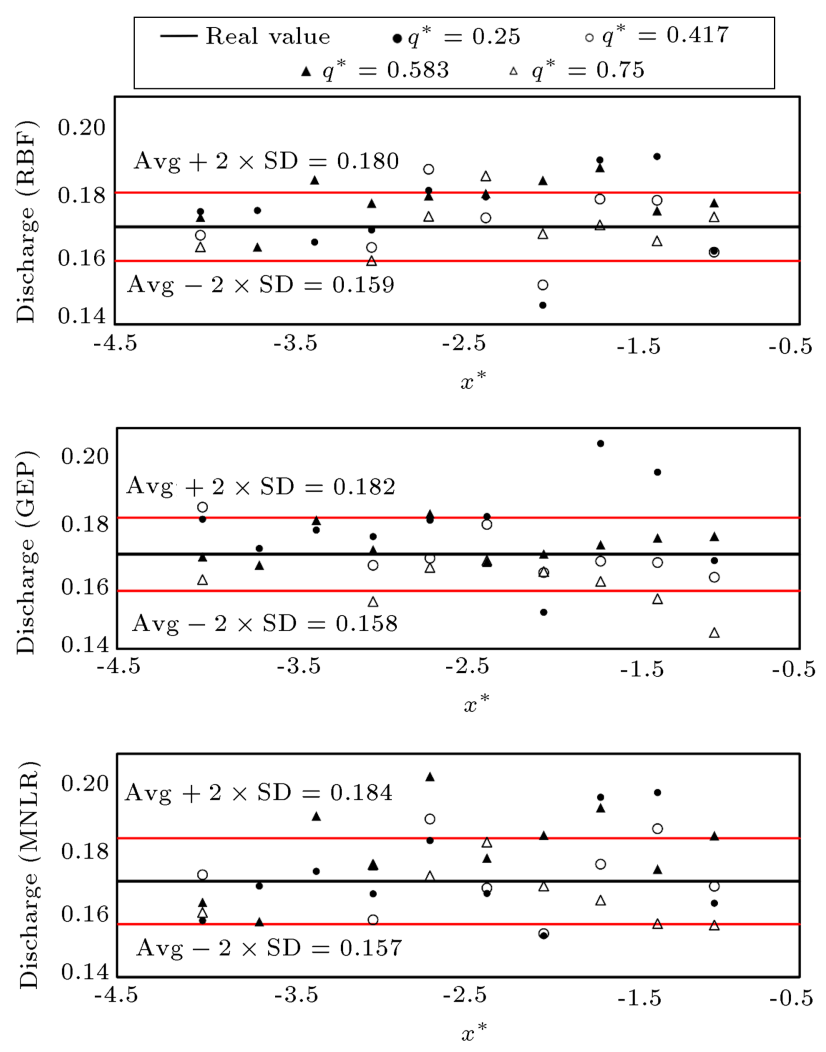

Figure 7. Discharge simulation with RBF, GEP, and MNLR models.

downstream flow was simulated. The results showed that despite the velocity prediction, the RBF method had higher accuracy in modeling the discharge than the GEP method. Therefore, it was concluded that a model with high accuracy in velocity field prediction might be weak in discharge simulation. In both velocity field and discharge simulations, the MNLR method performed significantly worse than the RBF and GEP methods, and it was concluded that this model could not be used in the complex velocity prediction around the junction. Considering the practical equations presented in this study as well as the non-dimensional input and output variables used in the models, the results of the investigated methods can be utilized in the future researches and practical situations.

\section{References}

1. Yen, B.C. "Hydraulics of sewers", Adv. Hydrosci., 14, pp. 1-122 (1986).

2. Yekani Motlagh, Y., Nazemi, A.H., Sadraddini, A.A., Abbaspour, A., and Yekani Motlagh, S. "Numerical investigation of the effects of combining sewer junction characteristics on the hydraulic parameters of flow in fully surcharged condition", Water. Environ. J., 27(3), pp. 301-316 (2013).

3. Mosley, M.P. "An experimental study of channel confluences", J. Geol., 84(5), pp. 535-562 (1976).
4. Ashmore, P. and Parker, G. "Confluence scour in coarse braided streams", Water. Resource. Res., 19(2), pp. 392-402 (1983).

5. Best, J.L. and Reid, I. "Separation zone at openchannel junctions", J. Hydraul. Eng., 110(11), pp. 1588-1594 (1984).

6. Biron, P., Roy, A., and Best, J. "Turbulent flow structure at concordant and discordant open-channel confluences", Exp. Fluids., 21(6), pp. 437-446 (1996).

7. Biron, P., Best, J.L., and Roy, A.G. "Effects of bed discordance on flow dynamics at open channel confluences", J. Hydraul. Eng., 122(12), pp. 676-682 (1996).

8. Kumar Gurram, S., Karki, K.S., and Hager, W.H. "Subcritical junction flow", J. Hydraul. Eng., 123(5), pp. 447-454 (1997).

9. Hsu, C.C., Wu, F.S., and Lee, W.J. "Flow at $90^{\circ}$ equal-width open-channel junction", J. Hydraul. Eng., 124(2), pp. 186-191 (1998).

10. Ramamurthy, A.S. and Zhu, W. "Combining flows in $90^{\circ}$ junctions of rectangular closed conduits", $J$. Hydraul. Eng., 123(11), pp. 1012-1019 (1997).

11. Weber, L.J., Schumate, E.D., and Mawer, N. "Experiments on flow at a $90^{\circ}$ open-channel junction", $J$. Hydraul. Eng., 127(5), pp. 340-350 (2001).

12. Taylor, E.H. "Flow characteristics at rectangular openchannel junctions", T. Am. Soc. Civ. Eng., 109(1), pp. 893-902 (1944).

13. Modi, P.N., Ariel, P.D., and Dandekar, M.M. "Conformal mapping for channel junction flow", J. Hydraul. Div., 107(HY12, Proc. Paper 16763), pp. 1713-1733 (1981).

14. Hager, W.H. "Transitional flow in channel junctions", J. Hydraul. Eng., 115(2), pp. 243-259 (1989).

15. Bradbrook, K.F., Biron, P.M., Lane, S.N., Richards, K.S., and Roy, A.G. "Investigation of controls on secondary circulation in a simple confluence geometry using a three-dimensional numerical model", Hydrol. Proces., 12(8), pp. 1371-1396 (1998).

16. Huang, J., Weber, L.J., and Lai, Y.G. "Threedimensional numerical study of flows in open-channel junctions", J. Hydraul. Eng., 128(3), pp. 268-280 (2002).

17. Shakibainia, A., Tabatabai, M.R.M., and Zarrati, A.R. "Three-dimensional numerical study of flow structure in channel confluences", Can. J. Civil. Eng., 37(5), pp. 772-781 (2010).

18. Bonakdari, H., Lipeme-Kouyi, G., and Wang, X. "Experimental validation of CFD modeling of multiphase flow through open channel confluence", World Environmental and Water Resources Congress 2011: Bearing Knowledge for Sustainability, pp. 2176-2183 (2011).

19. Mignot, E., Bonakdari, H., Knothe, P., Lipeme Kouyi, G., Bessette, A., Rivire, N., and Bertrand-Krajewski, J. "Experiments and 3D simulations of flow structures 
in junctions and their influence on location of flowmeters", Water. Sci. Technol., 66(6), pp. 1325 (2012).

20. Yang, Q.Y., Liu, T.H., Lu, W.Z., and Wang, X.K. "Numerical simulation of confluence flow in open channel with dynamic meshes techniques", Adv. Mech. Eng., 5 (2013).

21. Sharifipour, M., Bonakdari, H., Zaji, A.H., and Shamshirband, S. "Numerical investigation of flow field and flowmeter accuracy in open channel junctions", Eng. Appl. Comp. Fluid., 9(1), pp. 280-290 (2015).

22. Sharifipour, M., Bonakdari, H., and Zaji, A. "Impact of the confluence angle on flow field and flowmeter accuracy in open channel junctions", International Journal of Engineering-Transactions B: Applications, 28(8), pp. 1145 (2015).

23. Najafzadeh, M. and Bonakdari, H. "Application of a neuro-fuzzy GMDH model for predicting the velocity at limit of deposition in storm sewers", Journal of Pipeline Systems Engineering and Practice, p. 06016003 (2016).

24. Najafzadeh, M., Balf, M.R., and Rashedi, E. "Prediction of maximum scour depth around piers with debris accumulation using EPR, MT, and GEP models", Journal of Hydroinformatics, 18(5), pp. 867-884 (2016).

25. Kaydani, H., Najafzadeh, M., and Mohebbi, A. "Wellhead choke performance in oil well pipeline systems based on genetic programming", Journal of Pipeline Systems Engineering and Practice, 5(3), p. 06014001 (2014).

26. Najafzadeh, M., Laucelli, D.B., and Zahiri, A. "Application of model tree and evolutionary polynomial regression for evaluation of sediment transport in pipes", KSCE Journal of Civil Engineering, 21(5), pp. 1956-1963 (2016).

27. Najafzadeh, M., Tafarojnoruz, A., and Lim, S.Y. "Prediction of local scour depth downstream of sluice gates using data-driven models", ISH Journal of Hydraulic Engineering, 23(2), pp. 195-202 (2017).

28. Kisi, O. and Cigizoglu, H.K. "Comparison of different ANN techniques in river flow prediction", Civ. Eng. Environ. Syst., 24(3), pp. 211-231 (2007).

29. Bilhan, O., Emin Emiroglu, M., and Kisi, O. "Application of two different neural network techniques to lateral outflow over rectangular side weirs located on a straight channel", Adv. Eng. Software., 41(6), pp. 831-837 (2010).

30. Azamathulla, H.M., Ahmad, Z., and Ab. Ghani, A. "An expert system for predicting Manning's roughness coefficient in open channels by using gene expression programming", Neural. Comput. Appl., 23(5), pp. 1343-1349 (2013).

31. Zaji, A.H. and Bonakdari, H. "Application of artificial neural network and genetic programming models for estimating the longitudinal velocity field in open channel junctions", Flow. Meas. Instrum., 41, pp. 81-89 (2015).
32. Bonakdari, H. and Zaji, A.H. "Open channel junction velocity prediction by using a hybrid self-neuron adjustable artificial neural network", Flow Measurement and Instrumentation, 49, pp. 46-51 (2016).

33. Broomhead, D.S. and Lowe, D. "Radial basis functions, multi-variable functional interpolation and adaptive networks", Royal. Signals. Radar. Est. Memo., 4248 (1988).

34. Poggio, T. and Girosi, F. "Regularization algorithms for learning that are equivalent to multilayer networks", Science, 247(4945), pp. 978-982 (1990).

35. Buhmann, M.D., Radial Basis Functions: Theory and Implementations, Cambridge University Press Cambridge (2003).

36. Kisi, O. "The potential of different ANN techniques in evapotranspiration modelling", Hydrol. Proces., 22(14), pp. 2449-2460 (2008).

37. Koza, J.R. "Genetic programming as a means for programming computers by natural selection", Stat. Comput., 4(2), pp. 87-112 (1994).

38. Ferreira, C. "Gene expression programming in problem solving", In Soft. Comput. Indust., pp. 635-653, Springer (2002).

39. Ferreira, C. "Gene expression programming: A new adaptive algorithm for solving problems", Complex. Sys., 13(2), pp. 87-129 (2001).

40. Aytek, A. and Kisi, O. "A genetic programming approach to suspended sediment modelling", J. Hydrol., 351(3-4), pp. 288-298 (2008).

41. Ab Ghani, A. and Md Azamathulla, H. "Geneexpression programming for sediment transport in sewer pipe systems", J. Pipeline. Syst. Eng. Pract., 2(3), pp. 102-106 (2011).

42. Shiri, J. and Kisi, O. "Comparison of genetic programming with neuro-fuzzy systems for predicting short-term water table depth fluctuations", Comput. Geosci., 37(10), pp. 1692-1701 (2011).

43. Onen, F. "GEP prediction of scour around a side weir in curved channel", J. Environ. Eng. Landsc. Manage., 22(3), pp. 161-170 (2014).

44. Kisi, O., Dailr, A.H., Cimen, M., and Shiri, J. "Suspended sediment modeling using genetic programming and soft computing techniques", J. Hydrol., 450-451, pp. 48-58 (2012).

45. Isel, S., Dufresne, M., Bardiaux, J.B., Fischer, M., and Vazquez, J. "Computational fluid dynamics based assessment of discharge-water depth relationships for combined sewer overflows", Urban. Water. J., 11(8), pp. 631-640 (2014).

46. Regneri, M., Klepiszewski, K., Seiffert, S., Vanrolleghem, P.A., and Ostrowski, M. "Transport sewer model calibration by experimental generation of discrete discharges from individual CSO structures", iEMSs 2012 - Managing Resources of a Limited Planet: Proceedings of the 6th Biennial Meeting of the International Environmental Modelling and Software Society, pp. 3109-3116 (2012). 
47. Bonakdari, H. "Simple method for the estimation of discharge by entropy in narrow compound sewers", Can. J. Civil. Eng., 39(3), pp. 339-343 (2012).

48. Fach, S., Sitzenfrei, R., and Rauch, W. "Determining the spill flow discharge of combined sewer overflows using rating curves based on computational fluid dynamics instead of the standard weir equation", Water Sci. Technol., 60(12), pp. 3035-3043 (2009).

49. Oliveto, G. and Hager, W.H. "Discharge measurement in circular sewer", J. Irrig. Drain. Eng., 123(2), pp. 138-140 (1997).

50. Payne, J.A. and Hedges, P.D. "An evaluation of the impacts of discharges from surface water sewer outfalls", Water. Sci. Technol., 22(10-11), pp. 127-135 (1990).

\section{Biographies}

Amir Hossein Zaji is now PhD student in Civil Engineering with specialty in Hydraulic Structures in the Department of Civil Engineering, Razi University, Kermanshah, Iran. He has more than 30 published papers in ISI journals. He works in field of soft computing methods in engineering applications.

Hossein Bonakdari is Professor in the Department of Civil Engineering at Razi University. He received his PhD in Civil Engineering from University of Caen, France. After obtaining PhD, he joined Razi University as a faculty member in 2006 and, presently, he is a Full Professor in the Department of Civil Engineering. He has supervised $5 \mathrm{PhD}$ and $30 \mathrm{MS}$ theses with teaching experience of more than 16 years in the field of civil engineering. From 2010 to 2011, he was researcher at Laboratory of Civil and Environmental Engineering, INSA of Lyon, France; from 2011 to 2013, Deputy of Planning \& Development in National Water and Wastewater Engineering Company, Iran; and from 2013 to 2015, Director General of Training, Research and Technology Development at Ministry of Energy, Iran. His fields of specialization and interest include practical application of soft computing in engineering, modeling of wastewater urban drainage systems, sediment transport, computational fluid dynamics and hydraulics, design of hydraulic structures, and fluid mechanics. The results of his researches have been published in more than 130 papers in international journals (h-index $=13$ ). He has also more than 150 presentations in national and international conferences and 2 books. He has been rated as distinguished researcher at Razi University in 2014, 2015, and 2016. 